\title{
MARGIN DAN STRATEGI PEMASARAN KOMODITI JAGUNG DI KABUPATEN GORONTALO
}

\author{
Merita Ayu Indrianti \\ Program Studi Agribisnis, Fakultas Ilmu-Ilmu Pertanian, \\ Universitas Muhammadiyah Gorontalo, Gorontalo, 96181, Indonesia \\ Tel: +62-435-881135 Fax: +62-435-881136, E-mail: ayusutarto@umgo.ac.id \\ e-mail: ayusutarto@umgo.ac.id
}

\begin{abstract}
This research was conducted at Gorontalo district. The objective of this research is how the marketing margins and the marketing strategy of corn commodity at Gorontalo district. The result of the marketing margin that first (I) line has the big marketing margin Rp. 1.300 because the marketing line done by direct marketing. While for the low marketing margins contained on line III with margin Rp. O, because marketing in line III is the indirect marketing. From the result of analysis internal and external factor SWOT strategy that can be developed in corn marketing at Gorontalo district is diversification strategy that has value $X$ $=0,04$ and $Y=0,36$. Therefore strategy that recommended based on the priority scale are: 1). Facilitate the farmer to be able in access banking credit. 2). Motivate the farmer to more improve to farm the corn. 3). Provide coaching the technology of maize cultivation and post harvest handling.
\end{abstract}

Keywords: Strategy, Marketing of Corn Commodity

\section{PENDAHULUAN}

Rendahnya produksi jagung diakibatkan karena masih banyak petani jagung yang masih belum menggunakan varietas unggul dan masih minimnya modal petani sehingga petani jagung hanya meminjam modal kepada para tengkulak dan hasil jagung petani tersebut diserahkan kepada tengkulak serta cara bercocok tanam jagung ini juga belum memenuhi anjuran (Bambang, 2012).

Saluran pemasaran ini juga berpengaruh pada strategi komoditi jagung yang berada di Kabupaten Gorontalo, karena semakin panjang saluran pemasaran maka semakin besar pula biaya yang di keluarkan yang diakibatkan banyak pelaku-pelaku yang ikut serta dalam kegiatan pemasaran jagung tersebut, sehingga harga jagung yang sampai ke tangan petani atau produsen jagung tersebut harganya rendah. Saluran pemasaran merupakan cara atau sistem untuk menyampaikan produk yang dihasilkan oleh produsen kepada konsumen, dalam saluran pemasaran terdapat lembaga-lembaga pemasaran seperti produsen (petani), pedagang pengumpul, pedagang antar kota dan sebagainya Setiorini (2008) dalam Dadang (2011).

Pemasaran hasil produksi jagung yang berada di Kabupaten Gorontalo ke pasar lokal ditunjukkan untuk menghemat biaya pemasaran, namun terkadang keuntungan yang didapatkan oleh petani dan pedagang jagung masih rendah. Hal ini disebabkan harga jual jagung di tingkat petani rendah, upaya untuk memperbaiki tingkat harga yang diterima petani maka perlu dilakukan perbaikan tataniaga. Dengan demikian diperlukan distribusi jagung 
yang efektif dan efisien oleh lembaga pemasaran yang terlibat yaitu petani, pedagang perantara/pengumpul dan konsumen. Tujuan penelitian adalah untuk mengetahui margin pemasaran komoditi jagung di Kabupaten Gorontalo dan untuk mengetahui bagaimana strategi pemasaran komoditi jagung di Kabupaten Gorontalo.

\section{METODE PENELITIAN}

Metode yang digunakan dalam penelitian ini adalah metode kuantitatif. Penentuan sampel lokasi penelitian yang digunakan adalah metode purposive sampling yaitu pengambilan sampel lokasi secara sengaja di Kecamatan Tibawa, Kecamatan Bongomeme dan Kecamatan Mootilango.

Sampel dalam penelitian ini adalah kelompok petani jagung sebesar 10\% dari jumlah kelompok tani di tiga Kecamatan yaitu di Kecamatan Tibawa 15 responden, Kecamatan Bongememe sebanyak 16 responden dan di Kecamatan Mootililango 10 responden, sehingga total 41 responden. Sedangkan untuk penentuan sampel bagi pedagang pengumpul dan konsumen jagung dilakukan dengan teknik tracing sampel yaitu pengambilan sampel yang didasarkan atas informasi petani jagung, jumlah pedagang perantara/pengumpul dan konsumen.

Analisis data yang digunakan ada dua, yaitu analisis margin pemasaran dan analisis SWOT. Marjin pemasaran merupakan selisih harga ditingkat konsumen dan harga ditinggkat produsen. Untuk menghitung marjin dari setiap lembaga pemasaran digunakan rumus :

$$
\mathrm{Mp}=\operatorname{Pr}-\operatorname{Pf} \text { atau } \mathrm{Mp}=\mathrm{Bp}+\mathrm{Kp}
$$

Keterangan:

$\mathrm{Mp}=$ Marjin pemasaran $((\mathrm{Rp} / \mathrm{kg})$

$\operatorname{Pr}=$ Harga ditingkat pedagang $(\mathrm{Rp} / \mathrm{kg})$

Pf = Harga ditingkat petani $(\mathrm{Rp} / \mathrm{kg})$

$\mathrm{Bp}=$ Biaya Pemasaran $(\mathrm{Rp} / \mathrm{kg})$

$\mathrm{Kp}=$ Keuntungan Pemasaran $(\mathrm{Rp} / \mathrm{kg})$

\section{PEMBAHASAN}

Gambar 1 menunjukkan bahwa pada saluran ini produsen (petani jagung) menjual hasil produksi jagungnya kepada pedagang besar dengan harga Rp. 2.700/kg kemudian pedagang besar disalurkan lagi pada pedagang pengecer dengan harga 3.500/kg kemudian pedagang pengecer menjual kembali pada konsumen dengan harga Rp 4.000/kg sehingga dapat diketahui margin pemasaran jagung pada saluran I adalah Rp 1.300. Dapat dilihat pada Gambar 2 menunjukkan bahwa pada saluran ini produsen (petani) langsung menjual produksi jagungnya pada pedagang pengecer dengan harga $\mathrm{Rp} 2.800 / \mathrm{kg}$ kemudian pedagang pengecer menjual kembali pada para konsumen dengan harga Rp 4.000 sehingga dapat diketahui margin pemasaran jagung adalah Rp 1.200. Dapat dilihat pada Gambar 3 menunjukkan bahwa pada saluran III produsen (petani) langsung menjual jagungnya pada peternak ayam dengan harga Rp 3.500. Sehingga dapat diketahui margin pemasaran Rp 0. Karena saluran pemasarannya secara langsung. 


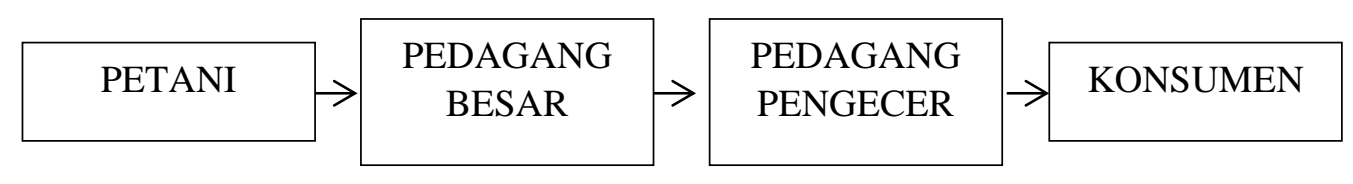

Gambar 1. Skema saluran pemasaran jagung di Kabupaten Gorontalo

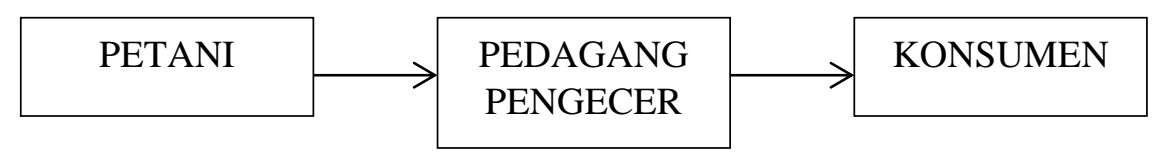

Gambar 2. Skema saluran pemasaran jagung di Kabupaten Gorontalo

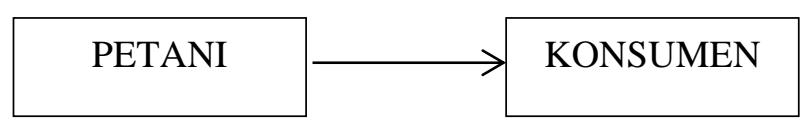

Gambar 3. Skema saluran pemasaran jagung di Kabupaten Gorontalo

Dapat dilihat pada Tabel 1 berdasarkan saluran pemasaran I di tiga Kecamatan yang memiliki margin pemasaran sebesar Rp 1.300, karena petani jagung menjual hasil jagungnya melalui perantara pedagang besar, dari pedagang besar kemudian di jual kembali pada pedagang pengecer setelah dari pedagang pengecer di jual lagi pada konsumen jagung. Dan pada saluran II petani menjual jagungnya pada pedagang pengecer, kemudian pedagang pengecer menjual kembali pada konsumen sehingga margin pemasarnya adalah Rp 1.300 dan pada saluran III petani langsung menjual jagungnya pada konsumen atau peternak ayam yang di gunakan untuk pakan ternak. Sehingga margin pemasarannya adalah Rp 0 karena saluran ini merupakan saluran pemasaran secara langsung.

Tabel 1. Margin Pemasaran Jagung di Kabupaten Gorontalo

\begin{tabular}{cccccc}
\hline No & $\begin{array}{c}\text { Lembaga } \\
\text { Pemasaran }\end{array}$ & $\begin{array}{c}\text { Pasar yang } \\
\text { dituju }\end{array}$ & $\begin{array}{c}\text { Harga Beli } \\
(\mathbf{K g})\end{array}$ & $\begin{array}{c}\text { Harga Jual } \\
(\mathbf{K g})\end{array}$ & $\begin{array}{c}\text { Margin } \\
\text { Pemasaran }\end{array}$ \\
\hline 1 & Pedagang besar & Pengecer & 2.700 & 3.500 & 1.300 \\
& Pengecer & Konsumen & & 4.000 & \\
2 & $\begin{array}{c}\text { Pedagang } \\
\text { pengecer }\end{array}$ & Konsumen & 2.800 & 4.000 & 1.200 \\
& & & & 0 \\
\hline
\end{tabular}

Sumber: Data Primer Setelah diolah, 2017

\section{Strategi Pemasaran Jagung di Kabupaten Gorontalo}

\section{Analisis Faktor Strategis Internal dalam Analisis SWOT}

Pada Faktor Internal Kekuatan dan Kelemahan memiliki total nilai Kekuatan 3,73 dan total nilai untuk Kelemahan 3,69 sehingga selisih Kekuatan-Kelemahan adalah 0,04. Dapat dilihat pada Tabel 2 Perhitungan Bobot, Skor dan Nilai Faktor Internal. Dapat dilihat pada Tabel diatas Selisih Kekuatan-Kelemahan adalah 0,04 dapat dilihat pada Tabel 2. 
Tabel 2. Analisis Faktor Strategis Internal dalam analisis SWOT

\begin{tabular}{|c|c|c|c|c|c|}
\hline No & Faktor Internal & $\begin{array}{c}\text { Bobot } \\
\text { (B) }\end{array}$ & $\begin{array}{c}\text { Skor } \\
(\text { S) }\end{array}$ & Nilai & Kode \\
\hline \multicolumn{6}{|c|}{ Kekuatan (S) } \\
\hline 1 & Lokasi penanaman jagung yang & 0.39 & 4 & 1.56 & S1 \\
\hline 2 & $\begin{array}{l}\text { Tingginya tingkat produktivitas usahatani } \\
\text { jagung }\end{array}$ & 0.27 & 3 & 0.81 & $\mathrm{~S} 2$ \\
\hline 3 & $\begin{array}{l}\text { Banyaknya jumlah petani yang } \\
\text { berusahatani jagung }\end{array}$ & 0.34 & 4 & 1.36 & S3 \\
\hline & Total Kekuatan & 1 & & 3.73 & \\
\hline \multicolumn{6}{|c|}{ Kelemahan (W) } \\
\hline 1 & Keterbatasan Modal yang dimiliki petani & 0.5 & 4 & 2 & W1 \\
\hline 2 & $\begin{array}{l}\text { Rendahnya tingkat pengetahuan dalam } \\
\text { hal budidaya dan paskapanen }\end{array}$ & 0.09 & 3 & 0.27 & W2 \\
\hline 3 & Kurangnya akses transportasi & 0.11 & 2 & 0.22 & W3 \\
\hline 4 & $\begin{array}{l}\text { Tidak adanya sarana teknologi } \\
\text { pengolahan hasil }\end{array}$ & 0.3 & 4 & 1.2 & W4 \\
\hline & Total Kelemahan & 1 & & 3.69 & \\
\hline & Selisih Kekuatan-Kelemahan & & & 0.04 & \\
\hline
\end{tabular}

Sumber: Data Primer Setelah diolah, 2017

\section{Analisis Faktor Strategi Eksternal dalam Analisis SWOT}

Pada Faktor Eksternal Peluang dan Ancaman memiliki total nilai Peluang 3,29 dan total nilai untuk Ancaman 3,65 sehingga selisih Peluang-Ancaman adalah -0,36. Dapat dilihat pada Tabel 3 Perhitungan Bobot, Skor dan Nilai Faktor Eksternal. Dapat dilihat pada Tabel 3.

Tabel 1. Analisis Faktor Strategi Eksternal Analisis SWOT

\begin{tabular}{|c|c|c|c|c|c|}
\hline No & Faktor Eksternal & $\begin{array}{c}\text { Bobot } \\
\text { (B) }\end{array}$ & $\begin{array}{c}\text { Skor } \\
\text { (S) }\end{array}$ & Nilai & Kode \\
\hline \multicolumn{6}{|c|}{$\begin{array}{c}\text { Peluang } \\
\text { (O) }\end{array}$} \\
\hline 1 & $\begin{array}{l}\text { Jagung merupakan komoditi unggulan di } \\
\text { Kabupaten Gorontalo }\end{array}$ & 0.5 & 4 & 2 & $\mathrm{O} 1$ \\
\hline 2 & Permintaan jagung cukup besar & 0.2 & 4 & 0.8 & $\mathrm{O} 2$ \\
\hline 3 & $\begin{array}{l}\text { Tingginnya harga jagung di tingkat } \\
\text { ekspor }\end{array}$ & 0.19 & 2 & 0.38 & $\mathrm{O} 3$ \\
\hline \multirow[t]{2}{*}{4} & Peluang pasar masih banyak & 0.11 & 1 & 0,11 & \\
\hline & Total Peluang & 1 & & 3.29 & \\
\hline \multicolumn{6}{|c|}{ Ancaman $(\mathrm{T})$} \\
\hline 1 & Harga jagung yang berfluktuasi & 0.8 & 4 & 3.2 & $\mathrm{~T} 1$ \\
\hline 2 & $\begin{array}{l}\text { Rendahnya tingkat pengetahuan dalam } \\
\text { hal budidaya dan paskapanen }\end{array}$ & 0.15 & 2 & 0.3 & $\mathrm{~T} 2$ \\
\hline \multirow[t]{3}{*}{3} & Kurangnya akses transportasi & 0.05 & 3 & 0.15 & $\mathrm{~T} 3$ \\
\hline & Total Ancaman & 1 & & 3.65 & \\
\hline & Selisih Peluang-Ancaman & & & -0.36 & \\
\hline
\end{tabular}

Sumber: Data Yang Sudah diolah 2017 


\section{Kombinasi Strategi Matriks SWOT}

Nilai total matrik faktor Internal dan faktor Ekstemal di gambarkan pada analisis SWOT. Dapat dilihat pada Tabel 4.

Tabel 4. Kombinasi Strategi Matriks SWOT

\begin{tabular}{|c|c|c|}
\hline Faktor Eksternal & $\begin{array}{l}\text { Kekuatan (Strenghts) } \\
\text { 1. Lokasi penanaman jagung } \\
\text { yang strategis } \\
\text { 2. Tingginya tingkat } \\
\text { Produktivitas usahatani } \\
\text { jagung } \\
\text { 3. Jumlah petani yang } \\
\text { menanam jagung sangat } \\
\text { banyak. }\end{array}$ & $\begin{array}{l}\text { Kelemahan (Weakness) } \\
\text { 1. Keterbatasan modal yang dimiliki } \\
\text { petani. } \\
\text { 2. Kurangnya pengetahuan petani } \\
\text { dalam hal budidaya dan paska panen. } \\
\text { 3. Kurangnya akses transportasi } \\
\text { 4. Tidak adanya sarana teknologi } \\
\text { pengolahan hasil }\end{array}$ \\
\hline $\begin{array}{ll}\text { Peluang (Opportunities) } \\
\text { 1. } \\
\text { Komoditi jagung } \\
\text { merupakan komoditi } \\
\text { unggulan di Provinsi } \\
\text { Gorontalo. } \\
\text { 2. Permintaan jagung } \\
\text { cukup besar. } \\
\text { 3. Harga jagung tinggi. } \\
\text { 4. Peluang pasar masih } \\
\text { banyak. }\end{array}$ & \begin{tabular}{ll}
\multicolumn{1}{c}{ Strategi S-O } \\
1. \\
Memaksimalkan lokasi yang \\
strategis dalam penanaman \\
jagung (S1, S2, O1) \\
2. $\begin{array}{l}\text { Meningkatkan luas areal } \\
\text { untuk penanaman jagung }\end{array}$ \\
(S2, O2) \\
3. Memotifasi petani agar \\
dapat menghasilkan kualitas \\
jagung yang sesuai standar \\
(S2, S3, O2, O4) \\
4. $\begin{array}{l}\text { Memperbaiki kualitas } \\
\text { jagung sehingga harga } \\
\text { jagung tinggi. (S1, S2, O3) }\end{array}$
\end{tabular} & \begin{tabular}{l}
\multicolumn{1}{c}{ Strategi W-O } \\
1. $\begin{array}{l}\text { Memfasilitasi petani dalam } \\
\text { peminjaman modal melalui kredit }\end{array}$ \\
perbankan ( W1, O3) \\
2. Partisipasi penyuluh lebih \\
ditingkatkan. (W2, O2) \\
3. Memperbaiki prasarana jalan desa \\
terutama lokasi produksi jagung. \\
(W3, W1, O2) \\
4. $\begin{array}{l}\text { menyediakan teknologi pengolahan } \\
\text { hasil terutama di sentra produksi } \\
\text { jagung. (W1, W4, O4) }\end{array}$
\end{tabular} \\
\hline $\begin{array}{l}\text { Ancaman (Threats) } \\
\text { 1. Hama dan penyakit } \\
\text { menyerang tanaman } \\
\text { jagung. } \\
\text { 2. Harga jagung } \\
\text { berfluktuasi. } \\
\text { 3. Iklim yang kurang } \\
\text { mendukung }\end{array}$ & $\begin{array}{l}\text { Strategi S-T } \\
\text { 1. Adanya pelatihan dan } \\
\text { partisipasi tenaga penyuluh } \\
\text { lebih di tingkatkan. (S2, } \\
\text { T1,T2) } \\
\text { 2. } \begin{array}{l}\text { Memotivasi petani untuk } \\
\text { menanam jagung lebih } \\
\text { ditingkatkan. (S1, S3, T1) }\end{array} \\
\text { 3. Penyesuaian proses produksi } \\
\text { dengan kondisi iklim yang } \\
\text { kurang mendukung. (S2, T3) }\end{array}$ & $\begin{array}{l}\text { Strategi W-T } \\
\text { 1. Memfasilitasipetaniagarmampumeng } \\
\text { akseskreditperbankan. (W1, W2, T1) } \\
\text { 2. Memberikan pembinaan teknologi } \\
\text { budidaya jagung dan penanganan } \\
\text { paska panen. (W2, W4, T1,T3) }\end{array}$ \\
\hline
\end{tabular}

Sumber: Data Yang Sudah diolah 2017

Setelah didapatkan hasil rumusan kombinasi alternatif strategi S-O, S-T, W-O, dan W-T dari lingkungan Internal dan Eksternal pada Tabel diatas. Rumusan alternatif strategi merupakan suatu alternatif yang digunakan perusahaan untuk menjalankan bisnis kedepannya. Berikut ini kombinasi strategi matriks yg didapat dari indikator hasil penggabungan pada faktor internal dan eksternal.

\section{Perumusan Alternatif Strategi}

Selanjutnya untuk menyususun formulasi alternatif-alternatif berdasarkan Matriks SWOT, alternatif yang disusun berdasarkan interaksi antara faktor Internal dan faktor Eksternal dalam pemasaran jagung di Kabupaten Gorontalo.

\section{Analisis SWOT untuk Strategi SO}

Dapat dilihat pada Tabel di atas bahwa strategi menggunakan semua kekuatan (S) untuk merebut peluang (O) sehingga memperluas pemasaran jagung di Kabupaten 
Gorontalo yaitu memaksimalkan lokasi yang strategis dalam penanaman jagung, meningkatkan luas areal untuk penanaman jagung, memotivasi petani agar dapat menghasilkan kualitas jagung yang sesuai standar dan memperbaiki kualitas jagung sehingga harga jagung tinggi.

\section{Analisis SWOT untuk Strategi WO}

Dimana strategi WO merupakan strategi yang disusun dengan cara meminimalkan kelemahan untuk memanfaatkan peluang untuk meningkatkan strategi pemasaran jagung di Kabupaten Gorontalo yaitu memfasilitasi petani dalam peminjaman modal melalui kredit perbankan, partisipasi penyuluh lebih ditingkatkan, memperbaiki prasarana jalan desa terutama lokasi produksi jagung, menyediakan teknologi pengolahan hasil terutama di sentra produksi jagung.

\section{Analisis SWOT untuk Strategi ST}

Strategi ST merupakan strategi yang disusun dengan cara menggunakan semua kekuatan untuk mengatasi ancaman yang datang dari luar. Adanya pelatihan dan partisipasi tenaga penyuluh lebih di tingkatkan, memotivasi petani untuk menanam jagung lebih ditingkatkan, penyesuaian proses produksi dengan kondisi iklim yang kurang mendukung.

\section{Analisis SWOT untuk Strategi WT}

Strategi WT merupakan strategi yang disusun dengan cara meminimalkan kelemahan untuk menghindari ancaman pemasaran jagung di Kabupaten Gorontalo dari segi lingungan memfasilitasi petani agar mampu mengakses kredit perbankan, memberikan pembinaan teknologi budidaya jagung dan penanganan pasca panen.

\section{KESIMPULAN DAN SARAN}

Hasil penelitian dan pembahasan mengenai analisis margin pemasaran jagung dan strategi pemasaran jagung di Kabupaten Gorontalo, diperoleh beberapa kesimpulan yaitu: 1) Hasil analisis margin pemasaran dapat diketahui bahwa saluran I memiliki margin pemsaran paling besar Rp1.300 karena saluran pemasaran yang dilakukan merupakan saluran pemasaran tidak langsung karena petani menyalurkan hasil produksi jagungnnya melalui perantara pedagang pengumpul, pedagang pengecer dan konsumen, sedangkan untuk margin pemasaran yang paling kecil yaitu terdapat pada saluran III dengan nilai margin pemasaran Rp 0, hal ini di sebabkan karena petani menjual langsung kepada konsumen dalam saluran pemasaran ini merupakan saluran pemasaran secara langsung 2) Dari hasil analisis faktor Internal dan Eksternal SWOT Strategi yang dapat dikembangkan dalam pemasaran jagung di Kabupaten Gorontalo adalah Diversifikasi strategi yang memiliki nilai $\mathrm{X}=0,04$ dan $\mathrm{Y}=$ 0,36. demikian stretegi yang direkomendasi berdasarkan skala prioritas adalah: 1) Memfasilitasi petani agar mampu mengakses kredit perbankan, 2) Memotivasi petani untuk menanam jagung lebih ditingkatkan, 3) Memberikan pembinaan teknologi budidaya jagung dan penangan pasca panen. 


\section{DAFTAR PUSTAKA}

Armstrong dan Kotler. 2003. Dasar-dasar Pemasaran, Jilid 1, Edisi Kesembilan. Jakarta: Penerbit PT. Indeks Gramedia.

Bambang, H. 2005. Strategi Manajemen. Jakarta: Bayumedia Publishing.

Balai Penyuluhan Pertanian, Perikananan dan Kehutanan (BP3K) Kecamatan Tibawa. 2015. Kabupaten Gorontalo.

Balai Penyuluhan Pertanian, Perikananan dan Kehutanan (BP3K) Kecamatan. Bongomeme. 2015. Kabupaten Gorontalo.

Balai Penyuluhan Pertanian, Perikananan dan Kehutanan (BP3K) Kecamatan. Mootilango. 2015. Kabupaten Gorontalo.

Bambang, W. 2012. Prospek dan Kendala Pengembangan Agribisnis Jagung di Propinsi Nusa Tenggara Barat. Jurnal Penelitian Pertanian Terapan, 12 (2): 103-114.

BM Prasanna, Maize. 2012. in the World: Trends, Challenges and Opportunities, Paparan disampaikan pada International Maize Conference: Gorontalo.

BPS [Badan Pusat Statistik]. 2015. Kabupaten Gorontalo. Kabupaten Gorontalo Dalam Angka 2015.

BPS. 2014. Provinsi Gorontalo dalam Angka. Badan Pusat Statistik Provinsi Gorontalo, Kota dan Kabupaten Gorontalo.

Dadang, S. 2011. Strategi Pengembangan Perikanan Tangkap Di Kabupaten Pacitan Berbasis Pada Distribusi Ikan yang di Daratkan di PPP Tamperan. Bogor. Institut Pertanian Bogor. [ Skripsi].

Hariyanto, M. 2013. Analisa Pengaruh Kepercayaasn Terhadap Tenaga Penjual (Trust In Employee), Dan Kepercayaan Terhadap Merek (Trust In Brand) Terhadap Niat Beli (Purchase Intention) Konsumen Pada Bernilai Furniture. Jurnal Manajemen Pemasaran Petra. 1 (2): 1-12.

Hunger, D dan Wheelen, T. 2003. Manajemen Strategi. Yogyakarta: Andi.

Ilato, R. 2014. Analisis Rantai Nilai Komoditas Jagung Serta Strategi Peningkatan Pendapatan Petani Jagung di Provinsi Gorontalo. Universitas Negeri Gorontalo. [Disertasi]

Kotler, P dan Gary, A. 2008. Prinsip-Prinsip Pemasaran. Jilid 1. Edisi Kedua Belas. Jakarta: Erlangga.

Nonik, K dan Nuning, S. 2014. Analisis Nilai Tambah dan Strategi Pemasaran Tortilla Chips Jagung Di Home Industry Insan Mandiri Klaten. Surakarta. Universitas Sebelas Maret.

Novianty, D. 2015. Strategi Manajemen Kepemimpinan Dalam Budaya Pemanfaatan Jagung Untuk Memperkaya Sumber Daya Genetik Pangan Masyarakat di Provinsi Gorontalo. Universitas Negeri Gorontalo. [Skripsi]

Nugroho, R. 2010. Perencanaan Strategis in Action. Jakarta: PT Elex Media Komputindo.

Rangkuti, F. 2011. Swot Balanced Scorecard. Jakarta: PT. Gramedia Pustaka Utama. 